FLÁVIA SUKEKAVA

Estudo comparativo da remodelação das estruturas do rebordo alveolar após elevação do retalho

São Paulo

2013 


\section{FLÁVIA SUKEKAVA}

Estudo comparativo da remodelação das estruturas do rebordo

alveolar após elevação do retalho

Versão corrigida

Tese apresentada à Faculdade de Odontologia da Universidade de São Paulo, para obter o título de Doutor, pelo Programa de Pós-Graduação em Ciências Odontológicas.

Área de Concentração: Periodontia

Orientador: Prof. Dr. Luiz Antonio Pugliesi Alves de Lima.

São Paulo 
Autorizo a reprodução e divulgação total ou parcial deste trabalho, por qualquer meio convencional ou eletrônico, para fins de estudo e pesquisa, desde que citada a fonte.

Catalogação da Publicação

Serviço de Documentação Odontológica

Faculdade de Odontologia da Universidade de São Paulo

Sukekava, Flávia.

Estudo comparativo da remodelação das estruturas do rebordo alveolar após elevação do retalho / Flávia Sukekava ; orientador Luiz Antonio Pugliesi Alves de Lima . -- São Paulo, 2013.

45 p. : fig., tab. ; $30 \mathrm{~cm}$.

Tese (Doutorado) -- Programa de Pós-Graduação em Ciências Odontológicas. Área de Concentração: Periodontia. -- Faculdade de Odontologia da Universidade de São Paulo.

Versão corrigida.

1. Rebordo alveolar. 2. Retalhos cirúrgicos. 3. Periodontia. 4.Tecidos Anatomia - Odontologia. I. Lima, Luiz Antonio Pugliesi Alves de. II. Título. 
Sukekava F. Estudo comparativo da remodelação das estruturas do rebordo alveolar após elevação do retalho. Tese apresentada à Faculdade de Odontologia da Universidade de São Paulo para obtenção do título de Doutor em Ciências Odontológicas ou Odontologia.

Aprovado em: 14/05/2012

\section{Banca Examinadora}

Prof. Dr. Luiz Antonio Pugliesi Alves de Lima

Instituição: FOUSP

Julgamento:

Prof. Dr. João Batista César Neto

Instituição: FOUSP

Julgamento:

Prof. Dr. Maurício Guimarães Araújo

Instituição: Universidade Estadual de Maringá Julgamento:

Prof. Dr. Leandro Chambrone

Instituição: Universidade de Guarulhos

Julgamento:

Prof. Dr. Mauro Ferreira Martins Tosta

Instituição: UNIFESP

Julgamento: 
Dedico este trabalho a toda a minha família, em especial ao meu marido por ter propiciado que meu sonho se tornasse realidade e participado ativamente de cada etapa de minha formação. Aos meus pais por todo o apoio e compreensão dedicados a mim durante mais essa etapa do meu caminho, entendendo as ausências, vibrando com as vitórias e torcendo juntos, sempre. E ao meu filho, Francisco, que me acompanhou desde quando eu nem sabia que ele estava por aqui. 


\section{AGRADECIMENTOS}

A Deus, que mais uma vez me trouxe até aqui.

Agradeço à Universidade Estadual de Maringá, em especial ao Departamento de

Odontologia, na figura do Prof. Dr. Maurício G. Araújo, ao Biotério Central e ao

COMCAP. Locais nos quais puder realizar as etapas iniciais desse trabalho;

Ao meu orientador, professor Luiz Lima por toda a atenção e confiança em mim depositadas;

Aos professores Dr. Victor Arana Chaves e Dr. Leandro Chambrone que fizeram observações fundamentais durante meu exame de qualificação, que foram acatadas prontamente;

Ao professor Dr. Claudio Mendes Pannutti que sempre esteve à disposição para me ajudar resolver minhas dúvidas estatísticas;

Aos professores Dra. Luciana Saraiva e Dr. João Batista Cesar Neto que me acolheram nas clínicas da graduação e dessa maneira pude vê-los muito mais de perto e aprender a admirá-los ainda mais.

Às meninas: Cecilia, (Ceci), Iracema (Nina), Regina, Márcia, Marília e Alessandra pela prontidão em me ajudar com os trâmites legais do processo;

À Universidade de Gotemburgo, nas figuras de Birgita Lillenberg e Jan Lindhe que permitiram que esse trabalho fosse realizado;

Aos amigos do laboratório de pesquisa em Periodontia-UEM: Livia Tolentino, Juliana Mesti, Mirieli Sipriano, Vitor Sapata e André Barbisan de Souza. 
Aos colegas da pós graduação da perio: dessa turma e de turmas passadas, meu muito obrigada pelo companheirismo.

Aos colegas de pós graduação da radio, da estômato, da patologia, da pediatria, da orto, da turma da teleodontologia.

A todos os professores da Disciplina de Periodontia desta universidade. 
"O pessimista se queixa do vento, o otimista espera que ele mude e o realista ajusta as velas."

Willian George Ward 


\section{RESUMO}

Sukekava F. Estudo comparativo da remodelação das estruturas do rebordo alveolar após elevação do retalho [tese]. São Paulo: Universidade de São Paulo, Faculdade de Odontologia; 2013. Versão corrigida.

O objetivo deste estudo foi descrever e comparar algumas características das estruturas alveolares após cirurgia de elevação de retalho. Cinco cães beagle tiveram seus segundos e terceiros pré-molares superiores raspados e alisados com instrumentos manuais e ultrassônicos. Do lado direito da maxila (Grupo teste) um retalho total foi elevado sobre o segundo e o terceiro pré-molares, de maneira a expor o osso alveolar até a junção muco-gengival, durante 15 minutos. Após esse período, os retalhos foram irrigados com soro fisiológico e retornados às suas posições iniciais e mantidos em posição com fio de sutura reabsorvível. Na região contralateral (Grupo controle), dentes/gengiva permaneceram intactos. Após três meses de cicatrização, os animais foram ortotanasiados e biópsias contendo tecidos mole e duro ao redor dos dentes foram obtidas das áreas teste e controle. Os blocos de biópsias foram preparados para analise morfométrica. Sobre os cortes, foram obtidas medidas lineares de ambos os grupos nos tecidos mole e duro, sendo que essas medidas foram obtidas em um, três e cinco milímetros abaixo da junção cemento-esmalte para: espessura do osso alveolar propriamente dito e do osso alveolar, espessura do ligamento periodontal e somente sobre tecido mole: espessura e altura gengival, comprimento do epitélio juncional. Valores médios e desvio padrão foram calculados usando o animal como unidade estatística. Teste $t$ de Student pareado foi utilizado sendo $p<0.05$ considerado como diferença estatisticamente significante. A análise morfométrica mostrou que noventa dias após elevação do retalho não havia mais sinais de modelação óssea e as dimensões dos tecidos moles e duros periodontais sofreram alterações, com diferença estatisticamente significante: espessura da gengiva supra-crestal e do osso alveolar propriamente dito e comprimento do epitélio juncional $(p<0.05)$. Os resultados sugerem que após elevação do retalho, espessura da gengiva supra-crestal, bem como o comprimento do epitélio juncional e altura da crista óssea sofreram alterações em suas dimensões significativamente; osso alveolar propriamente dito 
tem espessura constante ao longo do osso alveolar e também representa grande parte do osso alveolar em sua porção mais próxima à junção cemento-esmalte.

Palavras-chave: Histologia. Periodontia. Anatomia. 


\begin{abstract}
Sukekava F. Comparative study of dimensional alterations in alveolar ridge structures after flap elevation [thesis]. São Paulo: Universidade de São Paulo, Faculdade de Odontologia; 2013. Versão corrigida.
\end{abstract}

The aim of this study was to describe and to compare some characteristics of alveolar ridge structures after flap surgery. Five beagle dogs had their upper second and third premolars selected in both quadrants to be scaled and planned. On the right side (Test group) the buccal flap was elevated on the second and third premolar, exposing the alveolar bone, over the muco-gingival junction for 15 minutes. After that, the flaps were irrigated with saline and returned to the original position and sutured with bioabsorbable mattress. On the contra lateral side (Control group) the teeth and gingiva were maintained intact. After three months of healing, the dogs were sacrificed to provide biopsies containing soft and hard tissue around teeth. The biopsies were prepared for morphometrical analyses. At the sections some linear measurements were obtained from both groups over the soft tissue and one, three and five millimeters below the cement-enamel junction: bundle bone and alveolar bone thickness, periodontal ligament thickness. Only over the soft tissue: gingival thickness and height and junctional epithelium length were measured. Mean values and standard deviations were calculated using the dog as a statistical unit. Student's $t$ test was used $(p<0.05)$. The morphometric analyses have shown that 90 days after flap elevation there were no signs of bone modeling; and the dimensions of hard and soft tissues surrounding teeth had changed: gingival and bundle bone thickness; junctional epithelium length $(p<0.05)$. Conclusion: The results have shown that after flap elevation periodontal tissues had reduced permanently; thickness of keratinized gingiva, as well as junctional epithelium length and bone crest height suffered dimensional alterations; the bundle bone had a similar thickness along the alveolar bone and represented an important part of the alveolar crest close to the cementenamel junction.

Keywords: Histology. Periodontics. Anatomy. 


\section{LISTA DE ABREVIATURAS E SIGLAS}

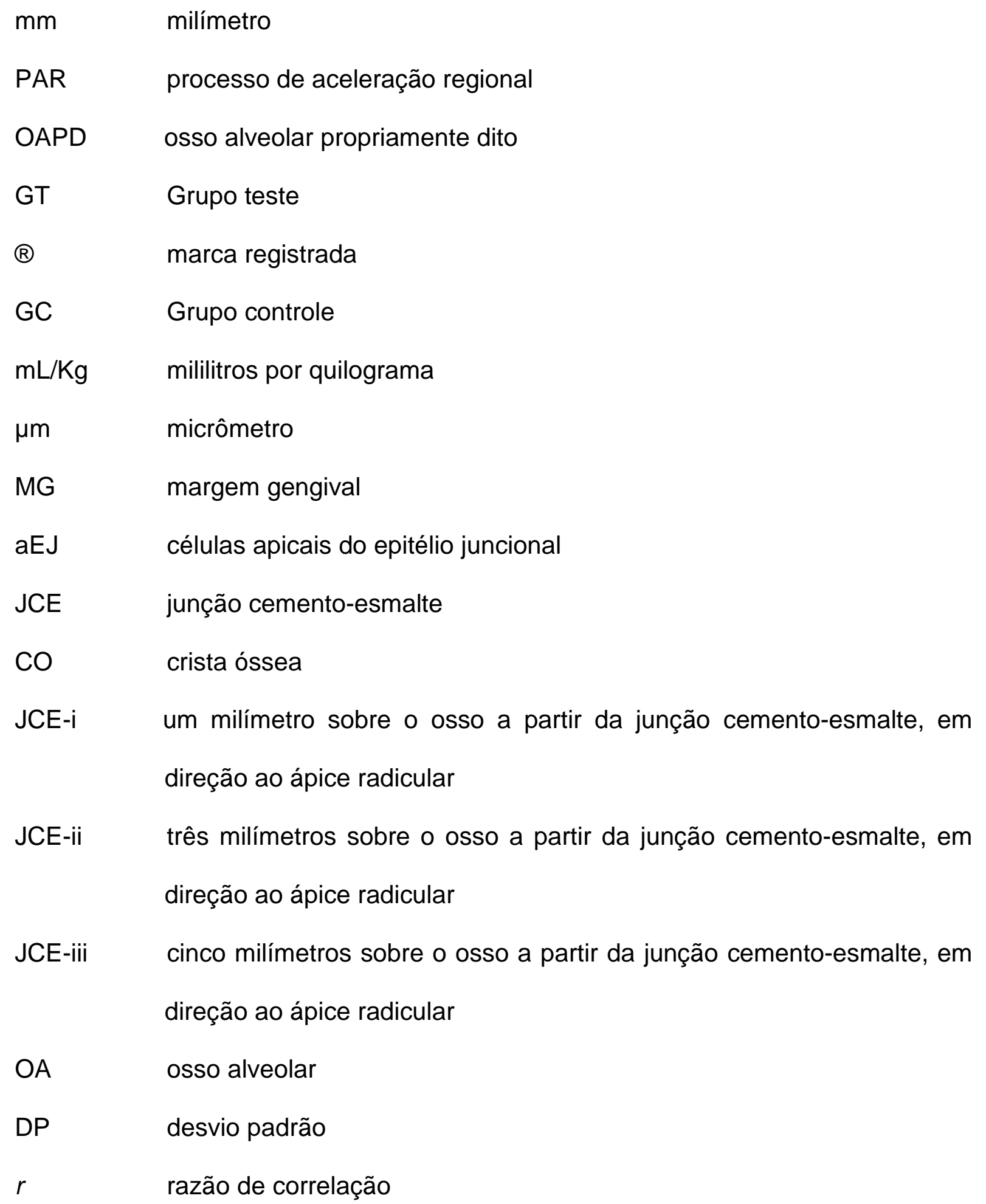




\section{LISTA DE TABELAS}

Tabela 6.1 - Medidas histométricas sobre tecido mole com média e desvio padrão (DP) para cada variável e grupo.....................................................32

Tabela 6.2 - Medidas histométricas sobre tecido duro com média e desvio padrão (DP) para cada variável e grupo.......................................................34

Tabela 6.3 - Relação espessura total do OAPD:OA em porcentagem. 


\section{LISTA DE FIGURAS}

Figura 5.1- Aspecto clínico do segundo e terceiro pré-molares superiores direito, Grupo teste (a); retalho mucoperiosteal elevado sobre o segundo e terceiro pré-molares superiores direito (b); dentes do Grupo teste com sutura em posição; segundo e terceiro pré-molares superiores direito, Grupo controle (d).

Figura 5.2- Desenho esquemático mostrando as marcações para tomada de medidas histométricas em tecido mole (a) e tecido mole e duro (b). JCE: junção cemento-esmalte; aEJ: células apicais do epitélio juncional; MG: margem gengival; CO: crista óssea. .24

Figura 6.1- Fotomicrografia de um corte no sentido vestíbulo-palatino representando Grupo teste. Observe porções de cemento radicular reabsorvido $\left({ }^{*}\right)$ após trauma cirúrgico, crista óssea deslocada em direção apical. CO: crista óssea; JCE: junção cemento-esmalte. Aumento original 5x. Coloração de Ladewig. .27

Figura 6.2- Fotomicrografia de um corte no sentido vestíbulo-palatino representando Grupo controle. Observe junção cemento-esmalte e epitélio juncional praticamente coincidentes. CO: crista óssea; JCE: junção cemento-esmalte. Aumento original 5x. Coloração de Ladewig. .28

Figura 6.3- Fotomicrografia de um corte no sentido vestíbulo-palatino representando Grupo controle, 3 milímetros abaixo da junção cementoesmalte. Observe a divisão nítida entre osso alveolar propriamente dito e osso alveolar. Aumento original 20x, filtro de luz polarizada. Coloração de Ladewig. 29

Figura 6.4- Fotomicrografia de um corte no sentido vestíbulo-palatino representando Grupo controle. Observe a relação de contato direto entre o osso alveolar propriamente dito e osso alveolar. CO: crista óssea; OA: osso alveolar; OAPD: osso alveolar propriamente dito;: fibras colágenas. Aumento original 10x. Coloração de Ladewig. 30 
Figura 6.5- Fotomicrografia de cortes no sentido vestíbulo-palatino representando Grupo teste nas três marcações: JCE-i (a),ii (b),iii (c). Observe as alterações sofridas no perfil da crista óssea. CO: crista óssea; JCE: junção cemento-esmalte. Aumento original 10x. Coloração de

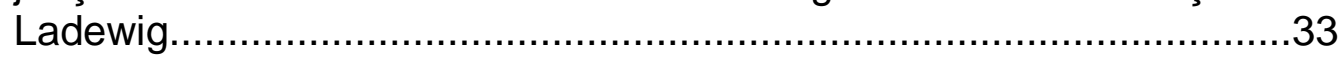




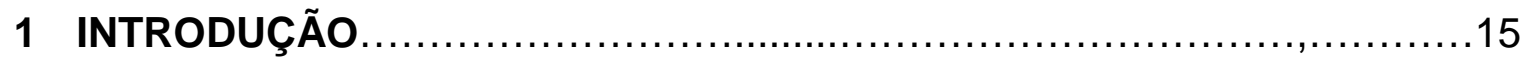

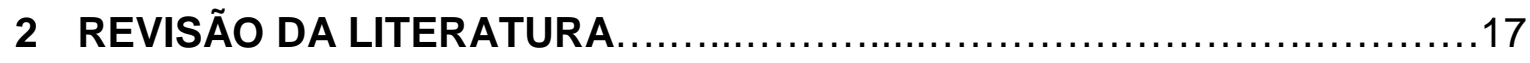

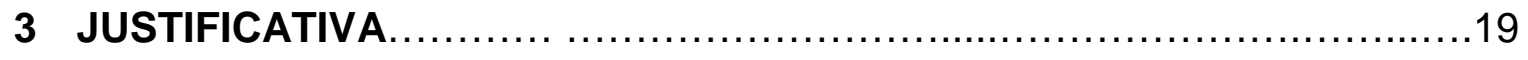

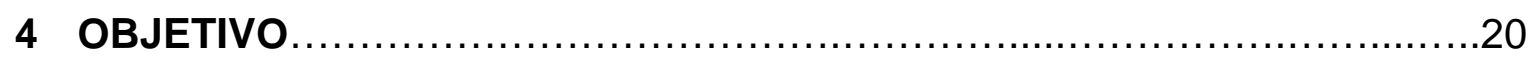

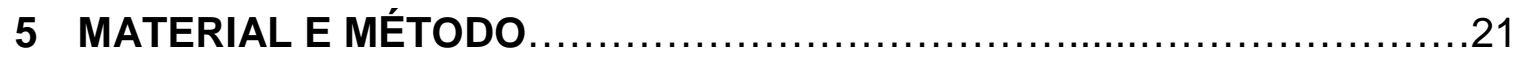

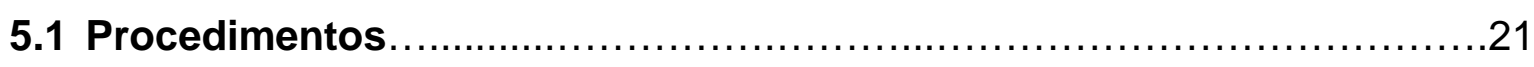

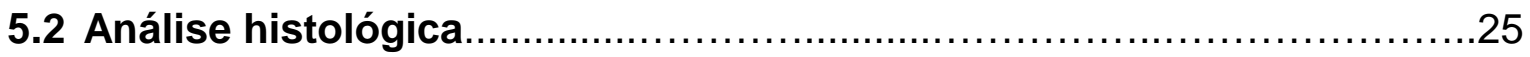

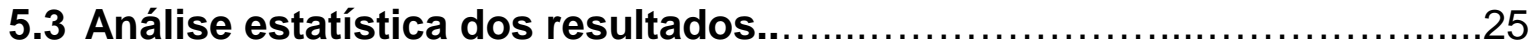

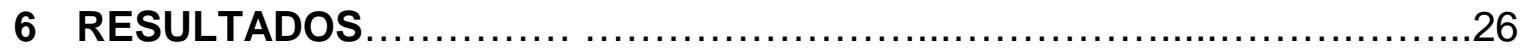

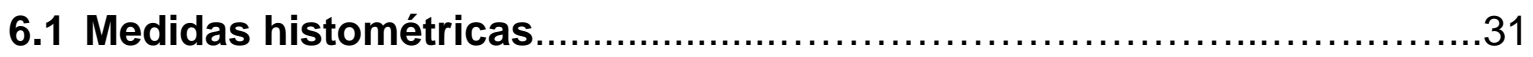

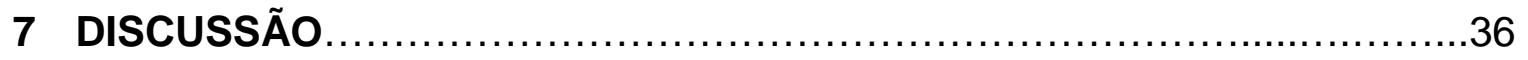

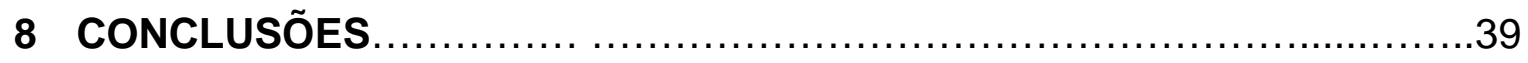

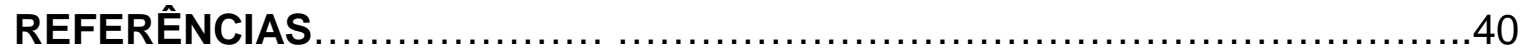

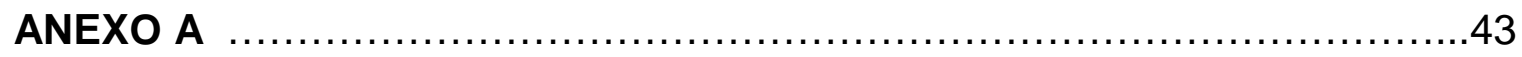

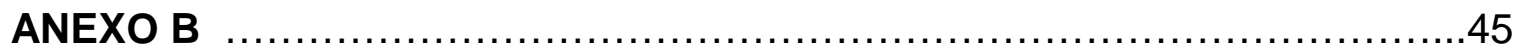




\section{INTRODUÇÃO}

O processo de cicatrização tecidual nos tecidos periodontais e suas alterações dimensionais que ocorrem após procedimentos cirúrgicos têm sido vastamente pesquisados em animais (Wilderman et. al., 1960; Wilderman 1963; Kon et al., 1969; Stahl et al., 1972; Stahl 1977; Sciubba et al., 1978; De Sanctis et al., 1988; Yaffe et al., 1994; Binderman et al., 2001; Nobuto et al., 2005; Fickl et al., 2008; Araújo; Lindhe, 2005, 2009) e os resultados sugerem que todas as vezes que intervenções cirúrgicas são feitas na gengiva, com ou sem exodontia, sempre há uma perda adicional de inserção.

Entretanto, apesar de já ter sido pesquisado o efeito da exodontia na remodelação do rebordo em animais (Araújo, Lindhe, 2005; 2009), há poucos trabalhos na literatura avaliando o efeito do acesso cirúrgico aos tecidos periodontais e a consequente remodelação da crista óssea alveolar através de microscopia (Wilderman et. al., 1960; Yaffe et al., 1994; Binderman et al., 2001). Avaliação pontual sobre as alterações dimensionais que ocorrem com a gengiva após elevação de retalho em modelos animais não foi encontrada na literatura corrente.

Ensaios clínicos que avaliaram a remodelação do rebordo após intervenção cirúrgica (Pfeifer 1963; Wilderman et. al., 1960; Wood et al., 1972; Rosling et al., 1976) para tratamento da doença periodontal, compararam técnicas cirúrgicas e concluíram que em todos os grupos houve uma pequena perda de inserção adicional. Deschner et al. (2009), por outro lado, avaliaram clinicamente o efeito da incisão intrasulcular nos tecidos periodontais de pacientes livres de perda de inserção prévia e após 10 meses de acompanhamento concluiu que, naquele desenho de estudo, não houve perda significativa de inserção.

Mas o que são os tecidos periodontais? Segundo Schroeder (1986) e Lindhe et al. (2008), são os tecidos que ancoram os dentes na mandíbula e maxila. Tendo como principal função inserir os dentes ao osso que os circundam e manter a integridade da superfície da mucosa mastigatória na cavidade bucal. É composto por: ligamento periodontal, cemento radicular, gengiva e processo alveolar. O processo alveolar pode ainda ser subdividido em osso alveolar propriamento dito (OAPD)/osso fasciculado e osso alveolar (OA). O processo alveolar se desenvolve em conjunto com o dente e seu irrompimento na cavidade bucal. É formado por 
células do folículo dental (osso alveolar propriamente dito) e células que são independentes do desenvolvimento dental. No osso fasciculado é possível observar lamelas circunferenciais, paralelas entre si e à superfície radicular e fibras principais do ligamento periodontal (fibras de Sharpey), perpendiculares ao osso alveolar propriamente dito e ao cemento radicular. No osso alveolar é possível observar a presença de ósteons, osteócitos, lamelas concêntricas e canais de Harvers. 


\section{REVISÃO DA LITERATURA}

A compreensão da anatomia e da função dos tecidos leva a um maior controle dos processos de cicatrização. Estudos sobre a estrutura, desenvolvimento e função dos tecidos periodontais têm sido feitos ao longo dos anos por diversos pesquisadores, relatados em detalhes por Schroeder (1986).

Em humanos, Pfeifer (1963), utilizando amostras provenientes de pacientes que sofreram cirurgias periodontais envolvendo retalho total, observou que a partir do 4ํ dia após exposição do osso, a crista óssea alveolar começou a mostrar sinais de reabsorção com redução média de $1 \mathrm{~mm}$ em altura e 0,2 $\mathrm{mm}$ em espessura. Nesse período, osteoclastos foram encontrados no osso medular e sobre o osso alveolar propriamente dito e aparentemente, o processo de formação de sequestro ósseo se estendeu até o 10 dia de cicatrização. A espessura do processo alveolar seria um fator importante na determinação do dano total que se segue ao acesso cirúrgico.

Pennel et al. (1967) utilizou 34 dentes condenados de 20 voluntários para estudar a remodelação da crista óssea após cirurgias periodontais e observou que após os procedimentos cirúrgicos, a redução média na altura da crista foi de $0,54 \mathrm{~mm}$.

Em um estudo clínico controlado, Wood et al. (1972), comparou o efeito da elevação de retalhos totais e retalhos parciais ao redor de 21 pares de dentes anteriores. Os resultados apresentados sugerem que mesmo sendo escolhido para execução o retalho parcial, houve redução da crista óssea, pois o tecido conjuntivo que ficou protegendo a parede óssea subjacente foi insuficiente para protegê-la do trauma causado pela cirurgia. Em média, houve redução de 0,98 mm no grupo retalho parcial e $0,62 \mathrm{~mm}$ no grupo retalho total, com diferença estatisticamente significante entre grupos.

Grande parte dos estudos em animais concorda com os resultados observados em humanos. Em animais, considerando somente estudos que não incluíram exodontia, Wilderman (1963) executou retalhos parciais em pré-molares superiores e inferiores de cães e observou que aos 90 dias de cicatrização o reparo ósseo na crista ocorreu completamente, inclusive com algumas áreas apresentando 
sinais de regeneração e com redução em altura e espessura da mucosa queratinizada.

Yaffe et al. (1994) avaliaram se o processo de aceleração regional (PAR) ocorre na mandíbula após elevação do retalho total e se esse fenômeno pode causar alterações significativas no osso alveolar. O PAR foi observado até três semanas depois do procedimento e quanto maior a extensão do procedimento, maior a reabsorção que foi observada inclusive no osso alveolar propriamente dito (OAPD).

Ainda em animais, Binderman et al. (2001) comparou a influência de retalhos totais a partir da região apical ou coronal, na face vestibular e lingual de molares inferiores de ratos, sobre a reabsorção do osso alveolar. Os autores observaram que em ambos os grupos houve alteração da crista óssea, porém esta remodelação foi mais acentuada no grupo que recebeu retalho total ao redor das coroas, especialmente na face voltada para o ligamento periodontal.

A resposta microvascular do periósteo de cães após elevação de retalho mucoperiosteal foi estudada por Kon et al. (1969), primeiramente e mais tarde por Nobuto et al. (2005). Seus resultados concordam em parte, pois ambos os estudos observaram que após elevação do retalho total o sistema vascular exibe uma resposta potente de formação de novos vasos com o intuito de aumentar a atividade reparadora na área traumatizada, levando muitas células de defesa que potencialmente podem se diferenciar em osteoclastos. 


\section{JUSTIFICATIVA}

Cirurgias envolvendo tecidos periodontais são extremamente frequentes. A compreensão da anatomia periodontal, bem como do processo cicatricial após essas intervenções são fundamentais para execução de um planejamento adequado e consequente obtenção dos resultados esperados. Há uma lacuna na literatura corrente a respeito da anatomia microscópica do osso alveolar propriamente dito e também sobre a modelação/remodelação dos tecidos periodontais após manipulação cirúrgica envolvendo incisões intra sulculares. 


\section{OBJETIVO}

O objetivo deste estudo foi avaliar as alterações dimensionais que ocorrem no osso alveolar e na gengiva supra-crestal de cães após a elevação de retalho total sem extração dentária. 


\section{MATERIAL E MÉTODO}

Este protocolo de pesquisa em experimentação animal utilizou biópsias viáveis e excedentes do protocolo de pesquisa "Efeito do enxerto de osso alógeno, xenogênico e aloplástico para a preservação do rebordo", aprovado pelo comitê de ética da Universidade Estadual de Maringá parecer número 08/2009 (Anexo A), sendo submetido à apreciação e aprovação do Comissão de Ética no Uso de Animais da Faculdade de Odontologia da Universidade de São Paulo (Anexo B).

Cinco cães beagle com um ano de idade aproximadamente e pesando cerca de $10 \mathrm{Kg}$ foram usados neste estudo. Durante os procedimentos, os animais foram anestesiados com administração intravenosa de Ketamina ${ }^{\circledR}$ (cloridrato de cetamina $10 \%$, Agener União, Brasil). Durante o período do experimento os animais foram alimentados com ração canina.

\subsection{Procedimentos}

Para a preparação dos sítios, todos os animais tiveram seus pré-molares e os primeiros molares superiores cuidadosamente raspados através de instrumento ultrassônico e ainda receberam escovação manual 3 vezes por semana com escova de dentes convencional e gel de clorexidina $0,12 \%$ até o fim do experimento.

Um mês após o procedimento de raspagem, os segundos e terceiros prémolares superiores direitos dos animais (Grupo teste-GT) (Figura 5.1a) receberam incisão intrasulcular na sua face vestibular e retalhos totais foram elevados com destaca periósteo até o limite da junção muco-gengival (Figura 5.1b) e, com auxílio de um destaca periósteo, mantidos nesta posição por 15 minutos. Passados 15 minutos, os retalhos foram lavados e retornados as suas posições originais e mantidos em posição com fio de sutura reabsorvível (Vicry®® 6.0, Ethicon® Johnson \& Johnson®, Reino Unido) (Figura 5.1c). O segundo e terceiro pré-molares superiores esquerdos foram considerados controle (Grupo controle-GC) (Figura $5.1 \mathrm{~d})$, tendo recebido somente os procedimentos de raspagem e controle de placa bacteriana. Por 15 dias após o experimento, os animais receberam ração canina 


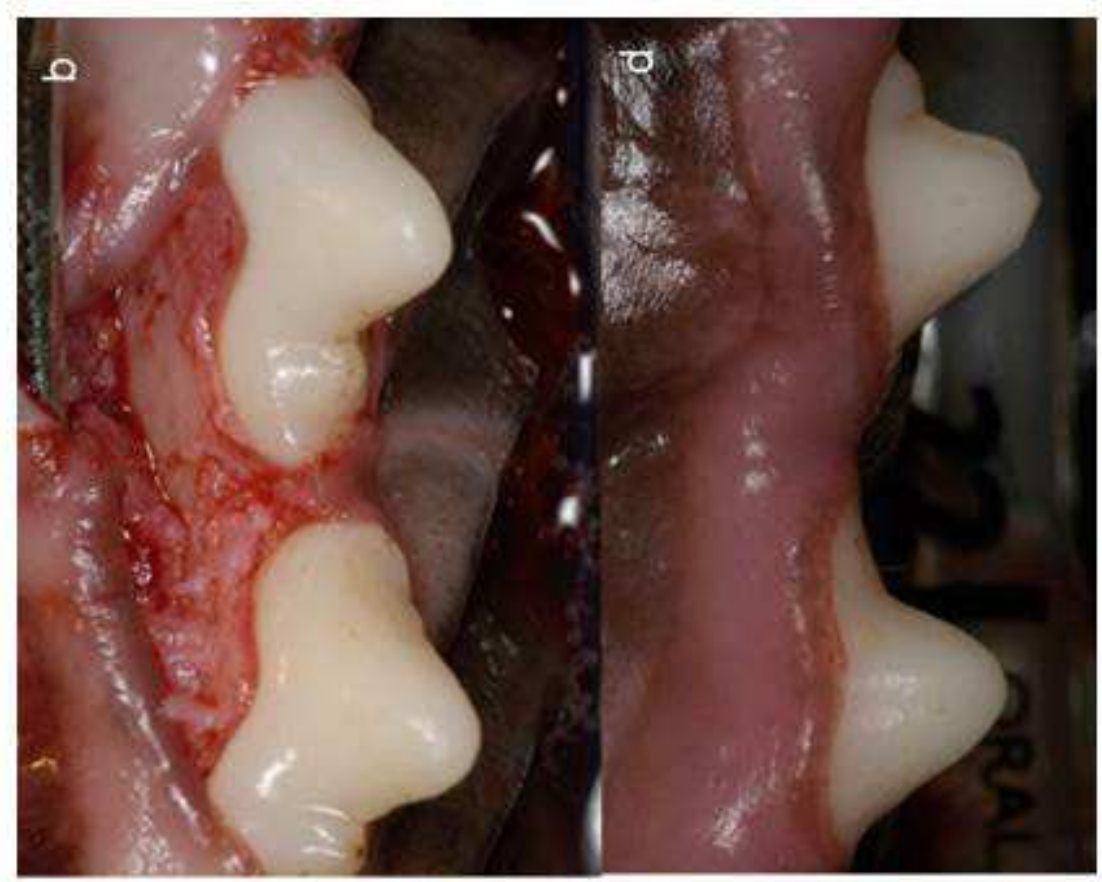

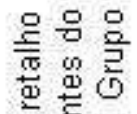
क熍 흠 옹요 을흠 寻嵒 学 믐

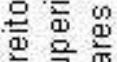
穷 o 9 产产迹 흥 동으 \%ั 은 i 产 응 옿음 d要 음 응 용 过 (1)음 을 뭉

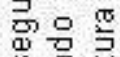
के 담

$8 \bar{\circ}$ 은응 웜 늉ㅎㅁ음 응 홀 त ह 08

$\frac{1}{40}$ 
pastosa e durante 10 semanas tiveram seus dentes escovados com escova manual de cerdas macias e gel de clorexidina $0,12 \%$, três vezes por semana. A ortotanásia foi executada 90 dias após o experimento de elevação do retalho. Para a ortotanásia, os animais receberam anestesia geral e foi administrado cloreto de potássio a 19\% (1 mL/Kg) através de injeção intravenosa. Após a constatação da cessação dos batimentos cardíacos dos animais, suas artérias carótidas foram perfundidas com um fixador contendo uma mistura de 5\% de glutaraldeído e $4 \%$ de paraformaldeído (Karnovsky, 1965). As maxilas foram cortadas de modo a separálas em blocos de biópsias contendo tecidos moles e duros da região dos pré-molares superiores. Cada bloco de biópsia foi desidratado em concentrações crescentes de etanol, embebidos em resina acrílica, cortados no plano vestíbulo-palatino e corados com solução de Ladewig (Donath, 1993).

A partir dos blocos de biópsias, foram obtidos cortes de $20 \mu \mathrm{m}$ de espessura, no plano vestíbulo-palatino, das raízes dos segundos e terceiros pré-molares superiores nos dois grupos (teste e controle). Foram marcados os seguintes pontos de referência nos cortes das raízes: margem gengival (MG), células apicais do epitélio juncional (aEJ), junção cemento-esmalte (JCE) (Figura 5.2a), crista óssea (CO) (Figura 5.2b) e a partir da junção cemento-esmalte, em direção ao ápice radicular, um (JCE-i), três (JCE-ii) e cinco (JCE-iii) milímetros sobre o osso alveolar. Foram efetuadas medidas lineares entre: MG-JCE, JCE-CO, aEJ-CO, aEJ-JCE e também foi calculada a espessura da gengiva supra-crestal no nível da JCE até a borda externa da gengiva que recobria parte da face vestibular das coroas clínicas dos pré-molares superiores de ambos os grupos.

A espessura total da parede vestibular do osso alveolar (OA), do OAPD, do ligamento periodontal e da proporção OAPD/OA foram calculadas nas seguintes marcações: JCE-i, JCE-ii, JCE-iii. Para tanto, foi obtida a média de três regiões de cada marcação (JCE-i, JCE-ii, JCE-iii) sendo essa $50 \mu \mathrm{m}$ coronais, apicais e sobre a marcação de referência. A média dessas medidas representou a medida linear do nível (JCE-i, JCE-ii, JCE-iii).

Além disso, para o cálculo da área em cada nível (JCE-i, JCE-ii, JCE-iii) também foram utilizadas as marcações de $50 \mu \mathrm{m}$ coronais e $50 \mu \mathrm{m}$ apicais à marcação de referência, totalizando uma região de $100 \mu \mathrm{m}$ de extensão. A área delimitada pelos reparos anatômicos que diferenciam OAPD e OA foi então calculada respeitando os limites anatômicos dentro dos 100 um de extensão. 

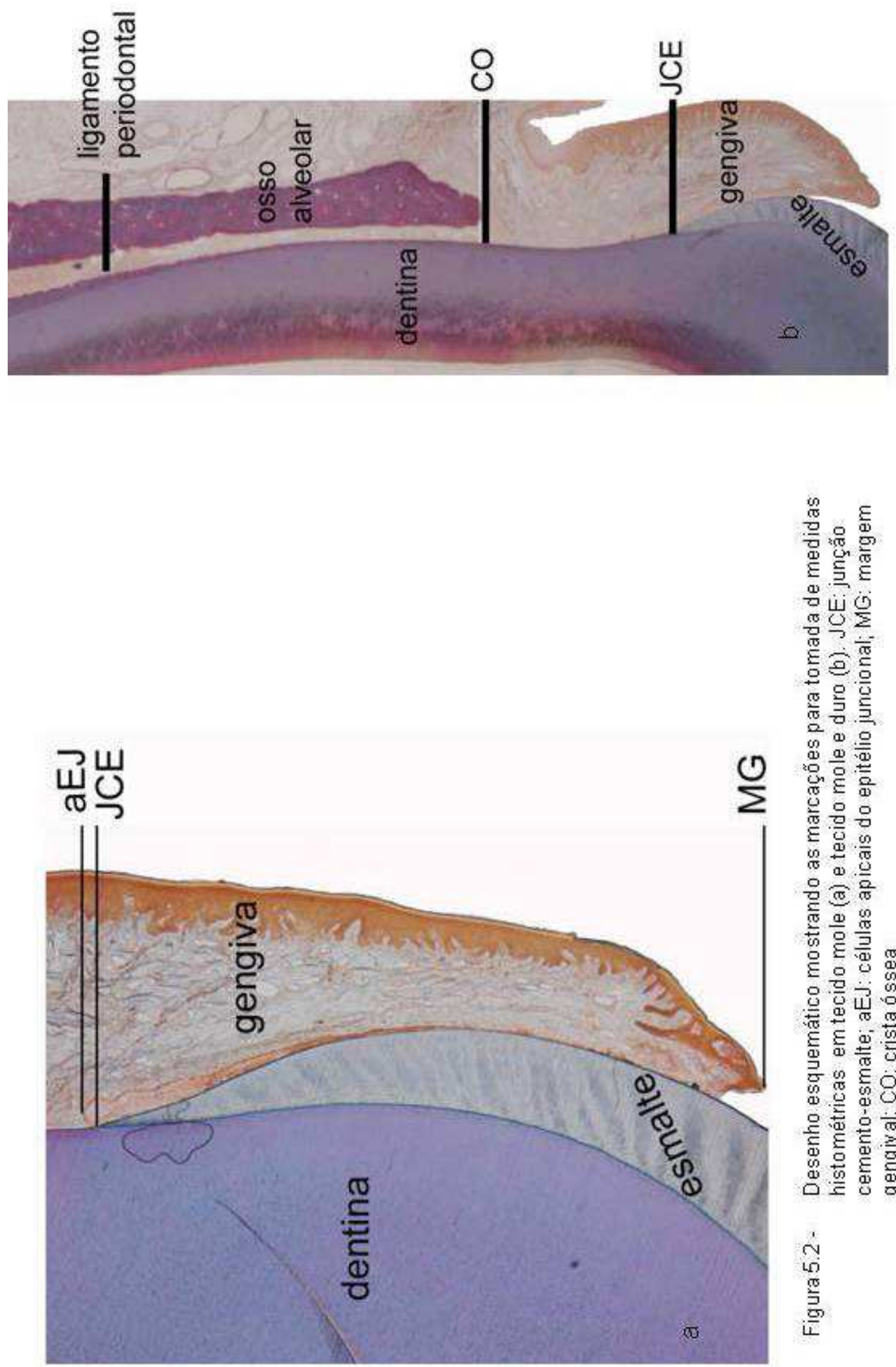

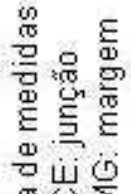

뜰

호웜

온

要寻年

으음

9 은.

总员

응ㅇㅁㅁㅇㅛ

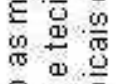

율 중

密

릉

둥ㅇㅇㅇ

응 흠

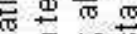

동

要

总

密家

部总

品怘

논 


\subsection{Análise histológica}

Os cortes dos locais experimentais foram examinados através de um microscópio óptico Axioskop 2 Plus ${ }^{\circledR}$ Zeiss (Carl Zeiss Light Microscopy, Göttingen, Alemanha) equipado com um sistema de imagens (AxioCam $\AA$; Carl Zeiss, Göttingen, Alemanha) e um programa (AxioVision® Carl Zeiss Microlmaging, Jena, Alemanha).

Para análise do osso alveolar propriamente dito foi utilizado filtro de luz polarizada, com aumento de 100 vezes (Schroeder, 1986).

\subsection{Análise estatística dos resultados}

A partir dos resultados obtidos foi calculada a média e o desvio padrão (DP) para cada dente, grupo e variável. Utilizando o programa Bio Estat 5.0 (Ayres et al., 2007) foi aplicado o teste Shapiro-Wilks para averiguar se houve distribuição normal dos dados e para testar se havia diferença estatística entre os grupos foi utilizado teste t pareado considerando $p<0,05$ como sendo a diferença entre os grupos estatisticamente significante. Para testar se havia associação entre duas variáveis no mesmo grupo foi utilizada correlação linear de Pearson, sendo que o valor de $r$ variando de 0,1 a 0,4 foi indicativo de fraca correlação; de 0,4 a 0,7, indicativo de correlação moderada e $>0,7$ indicativo de forte correlação entre as variáveis $(p<$ $0,05)$. Para as variáveis que não apresentaram adesão à curva de normalidade foi utilizada a correlação de Kendall para testar a hipótese de associação entre as mesmas $(p<0,05)$. 


\section{RESULTADOS}

Ao final de 90 dias de cicatrização foi observada ausência de sinais clínicos de inflamação. Para execução das medidas e comparações foram analisados 80 cortes histológicos, dos quais, três foram descartados por apresentarem erro de processamento.

No GT, em alguns cortes, foi observado histologicamente a presença de lacunas de reabsorção no cemento radicular e dentina na região compreendida entre JCE e CO (Figura 6.1) e da mesma forma, em alguns cortes, ainda foi possível observar a $\mathrm{CO}$ com lacunas de reabsorção em sua face voltada para o ligamento peirodontal. $\mathrm{O}$ epitélio juncional estava posicionado apicalmente à JCE, os feixes de fibras colágenas apresentaram-se estruturados e o epitélio do sulco estava íntegro sem sinais de ulceração.

No GC, histologicamente foi observada ausência de sinais de remodelação da CO, aJE e JCE posicionados de maneira quase sobreposta, feixes de fibras colágenas supra-crestais bem estruturados e epitélio juncional contínuo com epitélio do sulco e epitélio oral (Figura 6.2). Tanto o cemento radicular quanto a dentina apresentaram-se sem sinais de reabsorção em todos os cortes analisados.

$\mathrm{Na}$ maior parte dos espécimes analisados foi observado contato direto entre osso alveolar e osso alveolar propriamente dito até $3 \mathrm{~mm}$ abaixo da JCE (JCE-ii) (Figura 6.3) para ambos os grupos (Figura 6.3, Figura 6.4). 


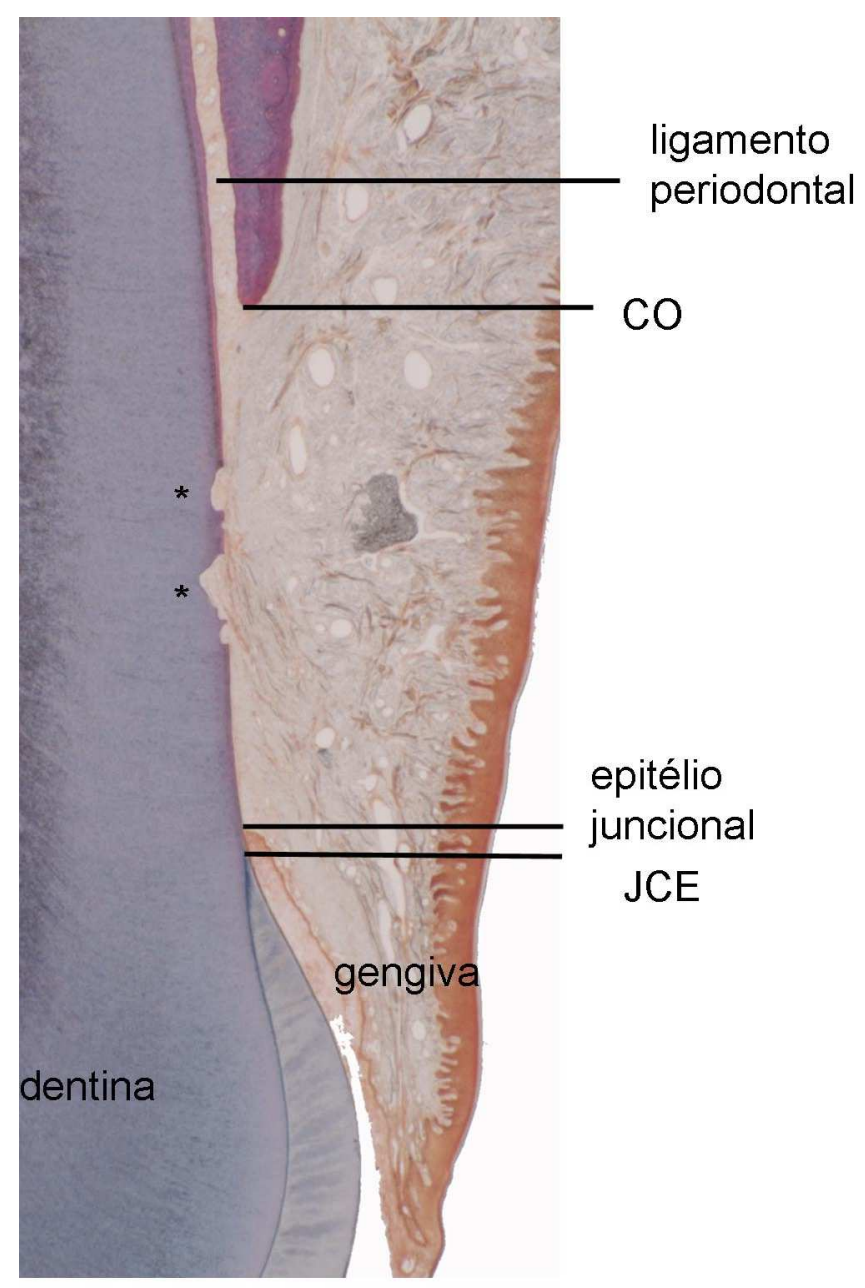

Figura 6.1- Fotomicrografia de um corte no sentido vestíbulo-palatino representando Grupo teste. Observe porções de cemento radicular reabsorvido ( ${ }^{*}$ ) após trauma cirúrgico, crista óssea deslocada em direção apical. CO: crista óssea; JCE: junção cemento-esmalte. Aumento original 5x. Coloração de Ladewig. 


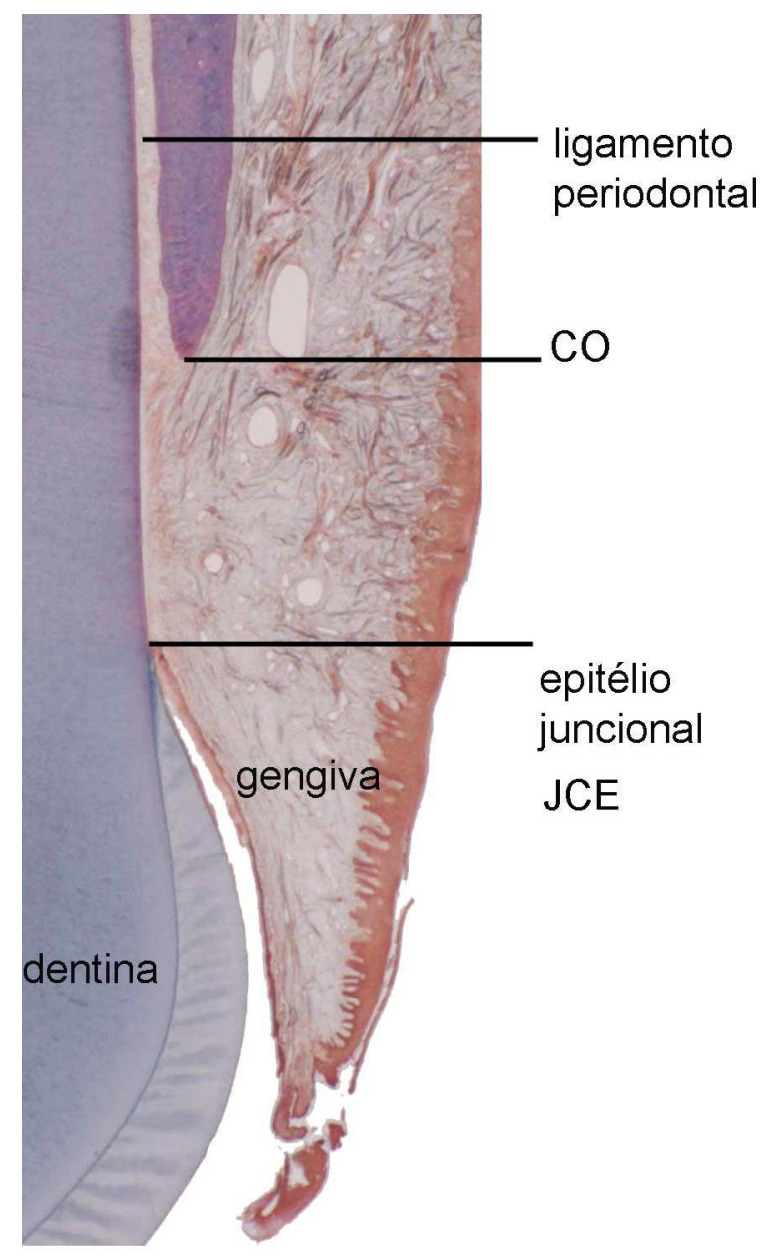

Figura 6.2- Fotomicrografia de um corte no sentido vestíbulo-palatino representando Grupo controle. Observe junção cementoesmalte e epitélio juncional praticamente coincidentes. CO: crista óssea; JCE: junção cemento-esmalte. Aumento original $5 x$. Coloração de Ladewig. 

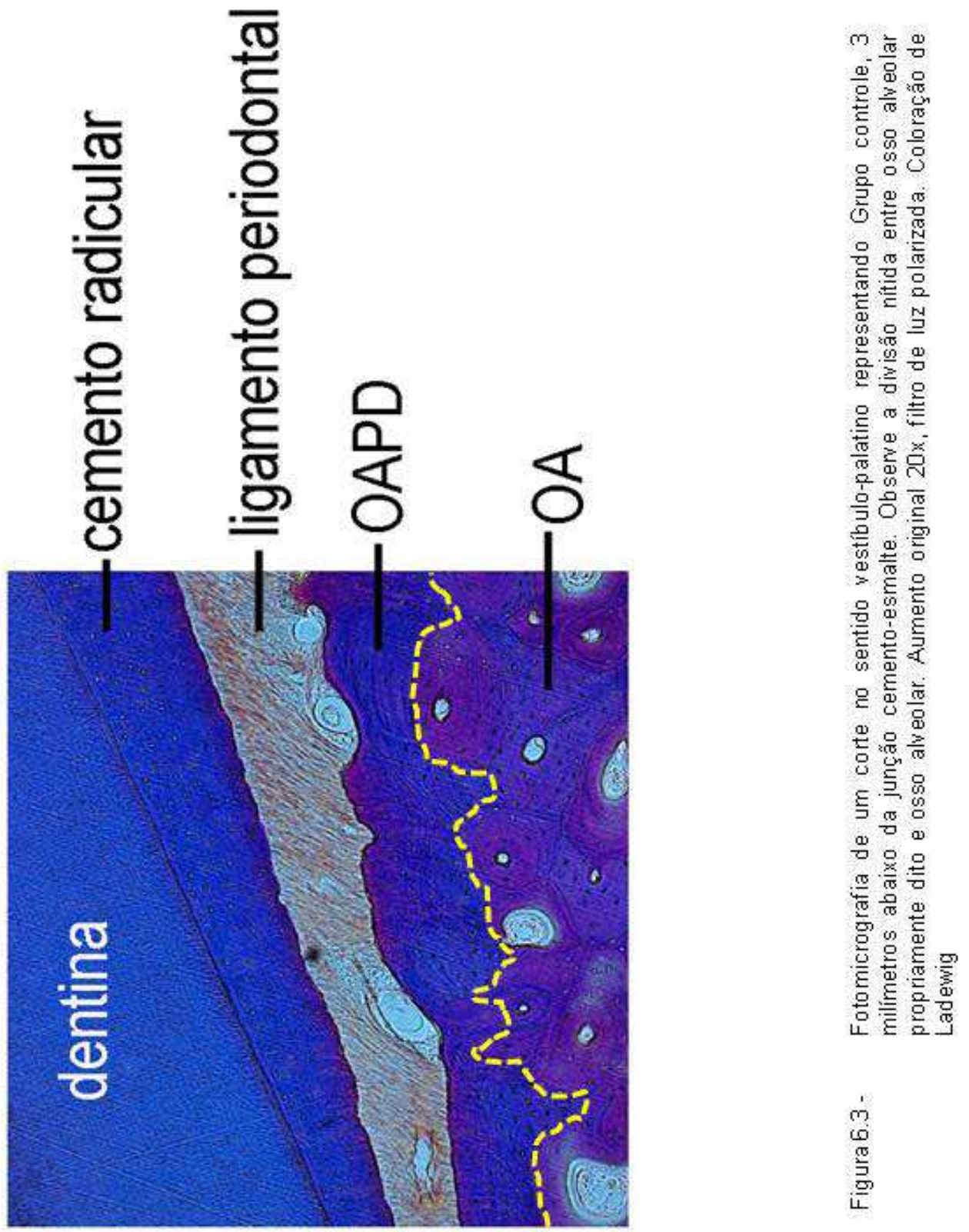


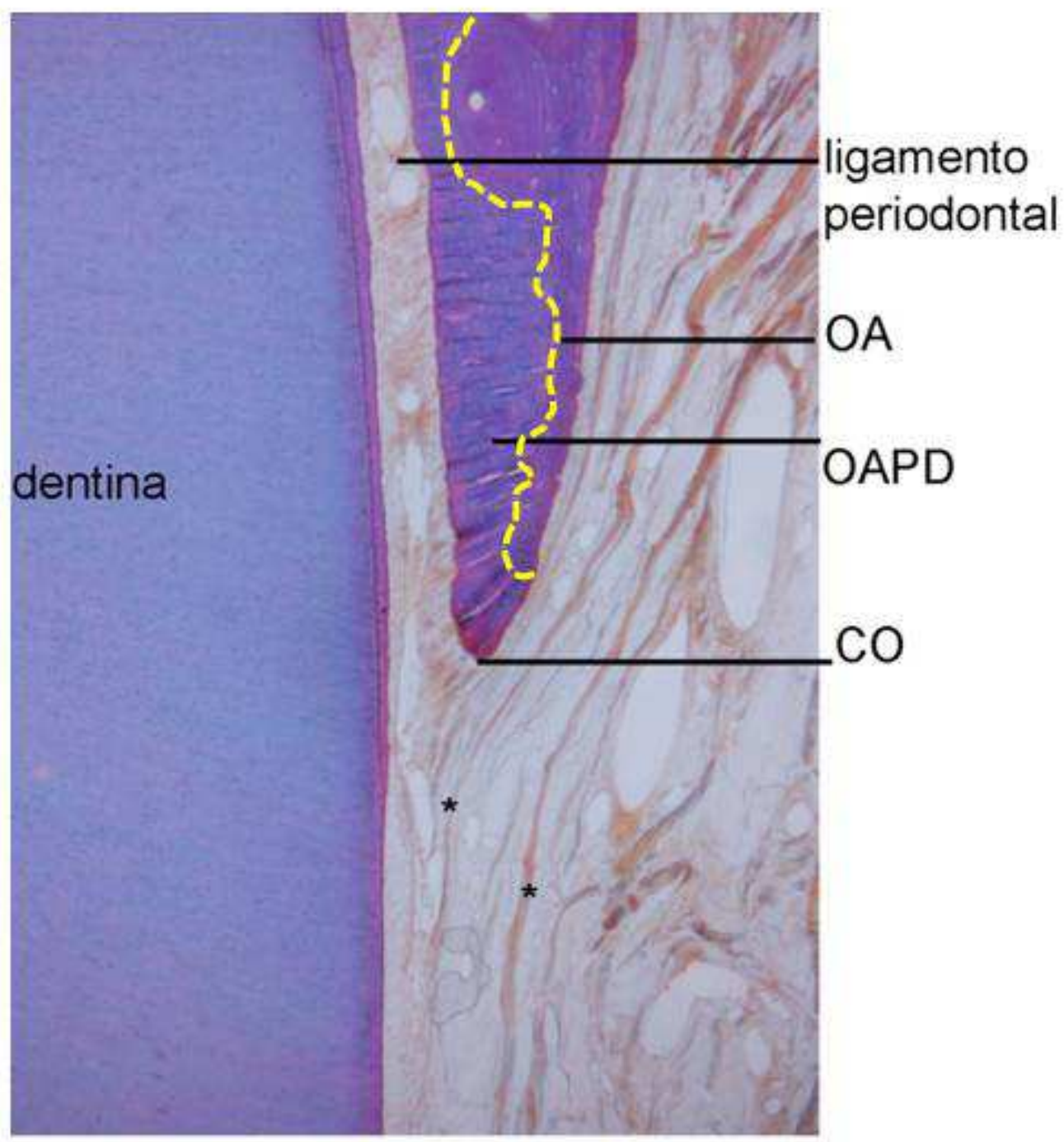

Figura 6.4 - Fotomicrografia de um corte no sentido vestíbulo-palatino representando Grupo controle. Observe a relaçẫo de contato direto entre o osso alveolar propriamente dito e osso alveolar. $\mathrm{CO}$ : crista óssea; $\mathrm{OA}$ osso alveolar; OAPD: osso alveolar propriamente dito; fibras colágenas. Aumento original 10x. Coloração de Ladewig 


\subsection{Medidas histométricas}

Na comparação das medidas lineares: MG-aEJ (GT: 2186,62 \pm 107,31 $\mu \mathrm{m}$;

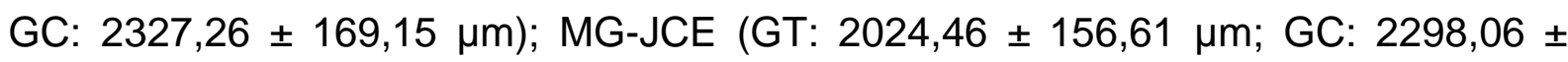

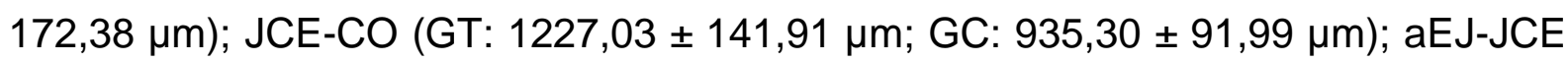

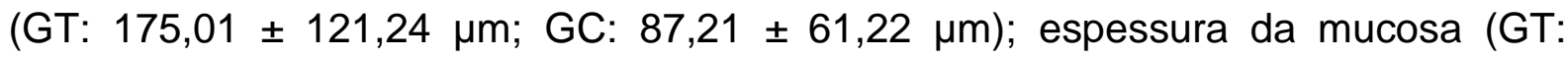
$1243,06 \pm 79,56 \mu \mathrm{m} ; \mathrm{GC}: 1127,90 \pm 102,80 \mu \mathrm{m})$; espessura do ligamento periodontal-ii (GT: 102,37 \pm 14,28 $\mu \mathrm{m}$; GC: 113,49 \pm 18,99 $\mu \mathrm{m}$ ) foi possível observar que entre GT e GC houve diferença estatisticamente significante $(p<0,05)$ (Tabela 6.1). A espessura do ligamento periodontal nas marcações i, ii e iii mostrou diferença estatisticamente significante $(p<0,05)$, entretanto, esta foi observada somente na marcação JCE-ii, sendo possivelmente uma coincidência numérica, sem importância clínica.

A medida JCE-i representa a espessura do processo alveolar $1 \mathrm{~mm}$ abaixo da

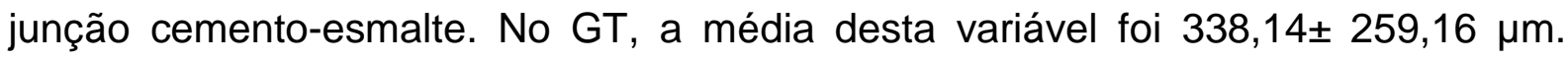
Neste grupo, dos cinco animais presentes, três apresentaram ausência de estrutura, indicando remodelação do rebordo, porém, um dos animais apresentou espessura superior a $500 \mu \mathrm{m}$ (Figura 6.5a), impactando diretamente na média do grupo. No GC, para a mesma medida, os valores variaram entre $209 \mu \mathrm{m}$ e $484 \mu \mathrm{m}$, com média $288,40 \pm 111,06 \mu \mathrm{m}$. As medidas de espessura da parede vestibular total do rebordo e da área da mesma região não mostraram diferença estatisticamente significante em JCE-i sugerindo que nas áreas onde o rebordo é mais espesso pode haver manutenção das estruturas após trauma cirúrgico (Tabela 6.2).

A razão encontrada para osso alveolar propriamente dito: osso alveolar (OAPD:OA) nas marcações JCE-i, ii, iii variou amplamente nas três regiões analisadas (GT: JCE-i: 13\%; JCE-ii: 12\%; JCE-iii: 7\%. GC: JCE-i: 27\%; JCE-ii: 16\%; JCE-iii: 10\%) pois apesar do OAPD também obedecer o padrão de aumento de espessura em direção apical, a porção vestibular do osso alveolar mostrou-se com espessamento ainda maior em direção apical (Tabela 6.3).

A correlação linear de Pearson mostrou correlação forte entre espessura do rebordo JCE-ii x espessura OAPD-ii no GT $(r=0,7 ; p=0,03)$ e correlação moderada no $\mathrm{GC}(r=0,5 ; \mathrm{p}=0,08)$ sugerindo que conforme há redução na espessura total do rebordo há consequente redução da espessura do OAPD; MG-CO x área JCE-i foi 


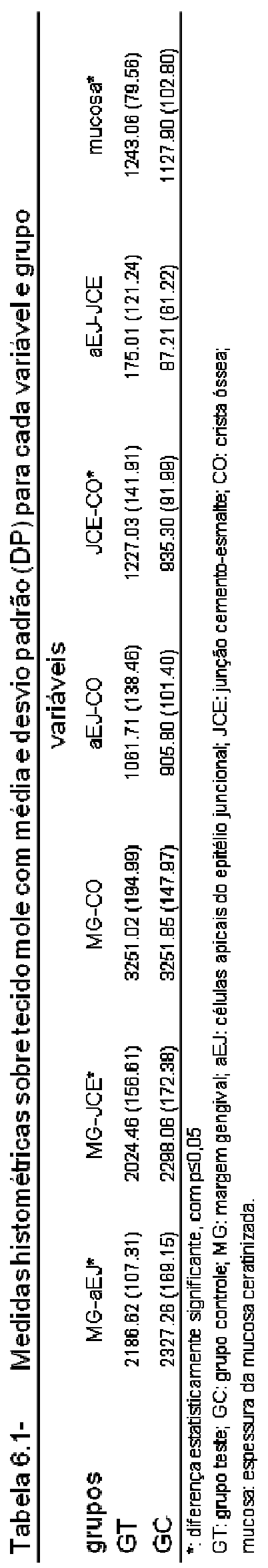




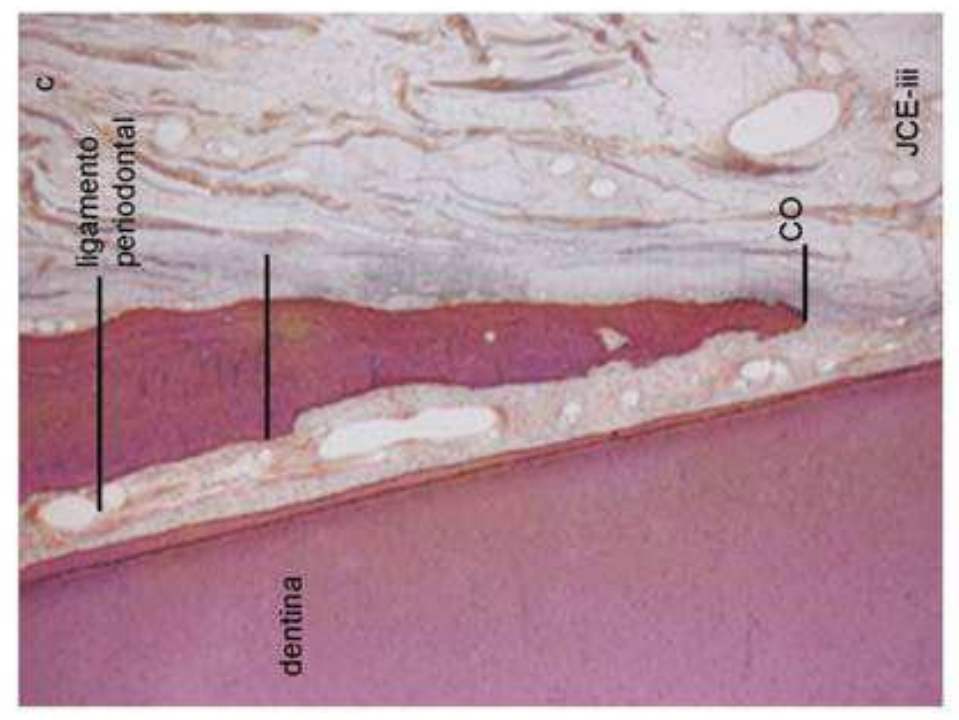

$\stackrel{9}{2} 8$

욤

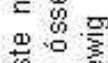

용

동

을 욤

0 응

을

플 응

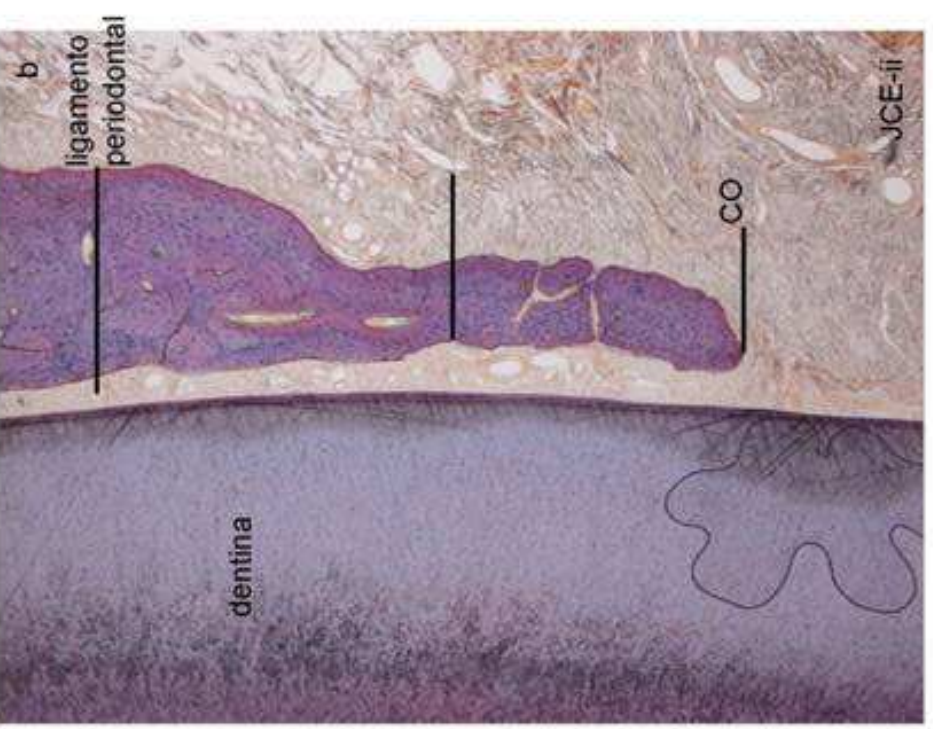

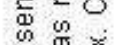

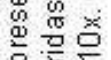

这客

․ㅡ

恙恕

空

군

윽 홍호

善品稀

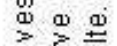

옹

올

\%

S

:ㅡㄹ

可

总:=要

옥

ฮ㓙

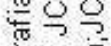

잉

(5)

을.

蛋弯
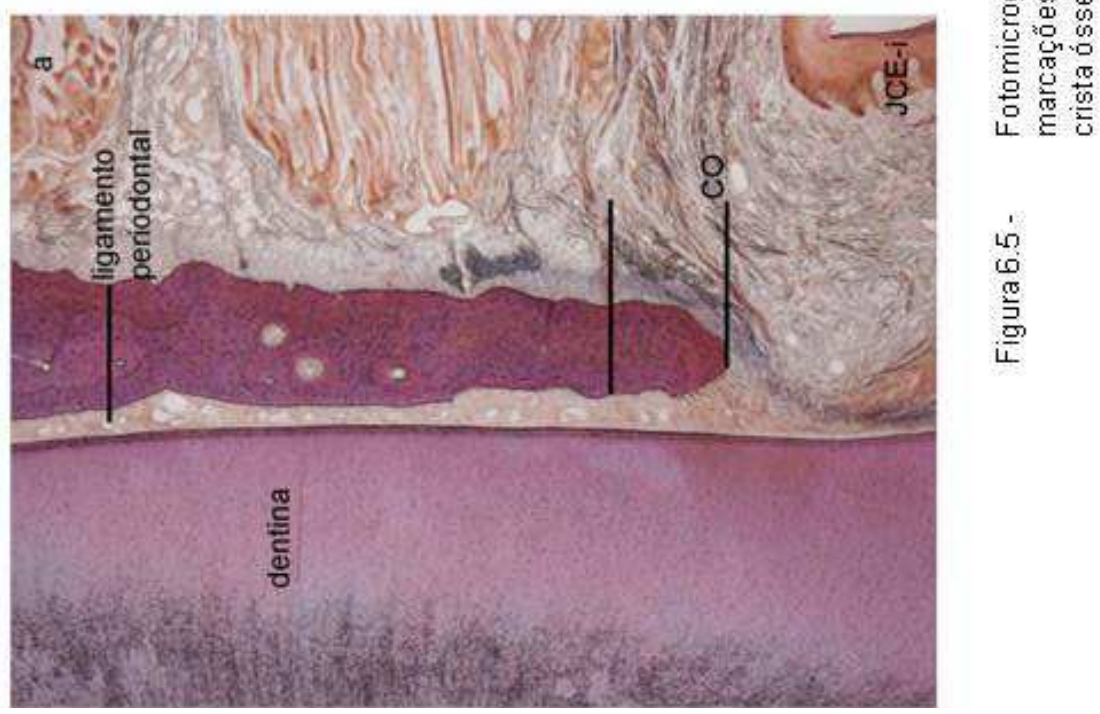

告 


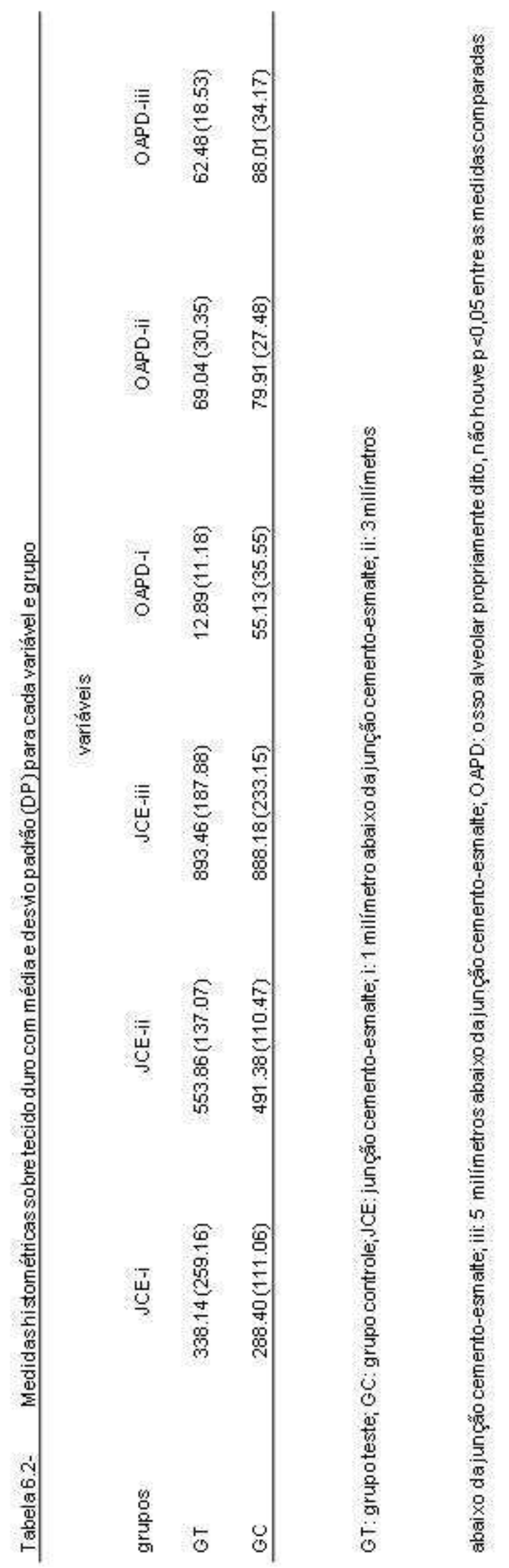


Tabela 6.3- Relação espessura total do OAPD:OA em porcentagem

\begin{tabular}{lcc}
\hline & \multicolumn{2}{c}{ grupos } \\
Regiões & controle & teste \\
JCE-i & 27 & 13 \\
JCE-ii & 16 & 12 \\
JCE-iii & 10 & 7 \\
\hline OAPD: osso alveolar propriamente dito; OA: \\
Osso alveolar; JCE: junção cemento-esmalte
\end{tabular}

considerada forte $(r=0,7 ; p<0,05)$ no $G T$, sugerindo que com a redução da área da crista óssea no primeiro milímetro mais cervical, a altura da gengiva supra-crestal também reduz; JCE-i $x$ espessura da mucosa mostrou correlação moderada ( $r=0,5$; $p>0,05$ ), sugerindo que com a redução da espessura da crista óssea a espessura da mucosa ceratinizada sofreu alteração. Para as variáveis: MG-CO x espessura da mucosa; MG-CO x JCE-ii; MG-CO $\times$ JCE-ii; espessura da mucosa $\times$ JCE-ii; espessura da mucosa $x$ JCE-iii; MG-CO $x$ área JCE-ii; espessura da mucosa $x$ área JCE-iii; JCE-iii x OAPD iii a correlação encontrada foi fraca $(r \leq 0,4)$. O coeficiente de correlação de Kendall $(p=0,02)$ indicou forte associação entre JCE-i x OAPD-i no GT. 


\section{DISCUSSÃO}

No presente estudo foram elevados retalhos mucoperiosteais na face vestibular dos segundos e terceiros pré-molares superiores do lado direito de cinco cães beagle adultos, sem exodontia (Figura 6.1a,b,c), e feitas comparações histológicas com os dentes contralaterais do mesmo animal que não sofreu qualquer intervenção cirúrgica (Figura 6.1d). Foram observadas alterações dimensionais tanto no tecido mole quanto no tecido duro após o procedimento cirúrgico (Figura 6.1), com diferença estatisticamente significante e O OAPD (Figura 6.3) nos cortes analisados mostrou uma espessura média inferior aos dados apresentados previamente na literatura por Schroeder (1986) de 0,3mm em média. Esta informação faz deste estudo o único e o primeiro a trazer à luz da ciência tal informação. Dados obtidos na literatura (Schroeder, 1986) sugerem medidas distintas daquelas encontradas, entretanto, essas informações foram obtidas a partir de inferências de estudos (Birn, 1966) que não tinham por objetivo avaliar tal estrutura. Em nosso estudo, as alterações observadas na proporção OAPD:OA sugerem que na porção mais coronal da crista óssea, na qual há maior presença de OAPD ( $27 \%$ no GC) a remodelação foi mais pronunciada, porém a partir de $3 \mathrm{~mm}$ abaixo da JCE não se observou mais qualquer alteração importante, inclusive mantendo espessura semelhante em direção apical, aproximadamente $16 \%$ no GC e $12 \%$ no GT, porém reduzindo seu valor proporcionalmente no processo alveolar em ambos os grupos (10\% GC e $7 \%$ GT), sem diferença estatisticamente significante.

O biótipo periodontal, espesso ou fino, pode ser determinante na quantidade de remodelação que ocorrerá na crista óssea alveolar após manipulação cirúrgica (Cook et al., 2011) pois osteoclastos presentes no ligamento periodontal e também no osso medular são ativados nessas condições (Pfeifer, 1963; Wilderman, 1963; Yaffe et al., 1994). Além disso, na região do periósteo previamente aderida à cortical vestibular do rebordo alveolar, que foi lesionada durante a elevação do retalho, ocorrerá uma resposta inflamatória, causando ativação de osteoclatos na superfície do osso alveolar (Wood et al., 1972; Flickl et al., 2008; Pfeifer, 1963; Wilderman, 1963) e essa ativação pode ocorrer também entre as corticais ósseas em função do PAR (Yaffe et al., 1994). Estudo recente em animais (Novaes et al., 2011) sugere que osso alveolar fino pode ser definido como sendo o osso no qual não há osso 
medular entre a cortical vestibular do osso alveolar e o OAPD. Em nossas amostras, provenientes da maxila de cães, os cortes sugerem que até $3 \mathrm{~mm}$ abaixo da JCE o osso alveolar está em íntimo contato com o OAPD, sem osso medular entre as duas corticais (Figura 6.4), sugerindo que se houver remodelação, esta ocorrerá concomitantemente na superfície das duas corticais: do OA e do OAPD.

As perdas em espessura e altura da crista óssea, observadas neste estudo, foram ligeiramente inferiores aos dados apresentados previamente por Wilderman (1963), o que pode ser justificado pelas diferenças entre as metodologias, pois neste estudo, não houve manutenção do periósteo, nem tampouco a agressão física com instrumentos rotatórios sobre as raízes. Além disso, Yaffe et al. (1994) observou que a remodelação do osso é diretamente proporcional à agressão sofrida. Nesse sentido, 15 minutos de exposição do processo alveolar é o equivalente a um acesso cirúrgico extremamente conservador e rápido, porém causando algum dano aos tecidos como observado nos resultados apresentados anteriormente.

Os resultados aqui apresentados, relacionados com a espessura do osso alveolar, de certa forma, estão de acordo com os resultados de Novaes et al. (2011), os quais demonstraram em animais que o OA aumenta em espessura no sentido apical. Entretanto, no estudo de Novaes et al. (2011) foram utilizados incisivos inferiores de cães sem raça definida e o local, a partir do qual iniciou-se a medida da espessura do osso alveolar não foi especificado, de maneira que as comparações entre os valores médios de espessura da tábua óssea vestibular apresentados no estudo mencionado e os dados encontrados neste estudo não podem ser feitas sem incorrer em erro. Em nosso estudo, o GC mostrou 27\% de OAPD em JCE-i e 16\% em JCE-ii (Tabela 6.3), e quase a totalidade das amostras apresentou OAPD e OA em íntimo contato (Figura 6.3, 6.4, 6.5), sem interposição de osso medular, o que caracterizaria, de acordo com Novaes et al. (2011), osso fino nessa região, com propensão a reabsorção após procedimento cirúrgico, como observado neste estudo da ordem de $0,5 \mathrm{~mm}$.

Os resultados das mensurações nas marcações em 3 e 5 mm abaixo da JCE, JCE-ii- e JCE-iii respectivamente, sugerem que nas regiões nas quais o retalho total não foi levantado, ou seja, onde não houve dano ao periósteo, também não houve remodelação do rebordo com redução permanente da espessura da crista óssea (Figura 6.5 a, b, c). Estudos sugerem que a exposição do osso alveolar durante as cirurgias com elevação de retalho mucoperiosteal (Wood et al., 1972; Flickl et al., 
2008; Pfeifer, 1963; Nobuto et al., 2005), ou mesmo retalhos parciais tão finos que não são capazes de proteger apropriadamente a cortical do rebordo alveolar (Wilderman, 1963; Wood et al., 1972), ou mesmo após raspagem e alisamento corono-radicular (Brägger et al., 1988), podem causar danos ao periósteo e colaboram com a maior remodelação do osso alveolar. Essas lesões ao periósteo causam um aumento da vascularização aumentando consequentemente o aporte de células de defesa para a área resultando em maior ativação de osteoclastos (Nobuto et al., 2005).

O animal que apresentou maior espessura da crista óssea em JCE-i também apresentou maior espessura da gengiva supra-crestal no mesmo lado. No geral, os animais que perderam altura de crista óssea ganharam em espessura de tecido mole, semelhante a um colapsamento da gengiva livre, e tal perda de tecido duro foi observada até o limite que o retalho foi elevado. Porém, nesta amostra, foi encontrada fraca correlação $(r<0,4)$ entre espessura da crista óssea e espessura da gengiva supra-crestal.

Os resultados sugerem que apesar de haver alteração na altura e espessura da gengiva supra-crestal, observadas histologicamente, mostrando que numericamente o GC mostrou gengiva mais espessa e alta, essas não apresentaram diferença estatisticamente significante, concordando com os resultados observados previamente em ratos (Binderman et al., 2001).

Alterações dimensionais foram observadas no OAPD na porção vestibular do rebordo, na região imediatamente abaixo do retalho elevado, no GT, sugerindo que mesmo em procedimentos simples que exijam a elevação do retalho total, sem exodontia, pode haver remodelação do osso fasciculado e que em áreas nas quais esse osso representa a maior parte do processo alveolar, resultaria em deiscência óssea importante. Estudos em animais sugerem que nas primeiras seis semanas após o procedimento cirúrgico já é possível observar histologicamente todo o potencial regenerativo da crista óssea e que aos 90 dias de cicatrização os tecidos periodontais podem ainda, exibir algum grau de inflamação (Kon et al., 1969). 


\section{CONCLUSÃO}

Os resultados sugerem que algumas alterações que ocorrem no tecido mole após manipulação do retalho total, sem a presença de incisões relaxantes, são estatisticamente significativas. Com relação ao tecido duro, na porção mais cervical, onde há maior proporção de OAPD há maior remodelação, com perda dessa estrutura. Além disso, esta estrutura tem espessura uniforme ao longo do alvéolo, parecendo exercer função importante no processo de remodelação da crista óssea após procedimento cirúrgico. 


\section{REFERÊNCIAS ${ }^{1}$}

Araújo MG, Lindhe J. Dimensional ridge alterations following tooth extraction. An experimental study in the dog. J Clin Periodontol. 2005;32(2):212-8.

Araújo MG, Lindhe J. Ridge alterations following tooth extraction with and without flap elevation. An experimental study in the dog. Clin Oral Implants Res. 2009;20(6):545549. doi: 10.1111/j.1600-0501.2008.01703.x.

Ayres M, Ayres-Junior M, Ayres DL, Santos AAS dos. Bio Estat. Aplicações estatísticas nas áreas das ciências médicas. Tefé: Ed Mamirauá; 2007. 339p.

Binderman I, Adut M, Zohar R, Bahar H, Faibish D, Yaffe A. Alveolar bone resorption following coronal versus apical approach in a mucoperiosteal flap surgery procedure in the rat mandible. J Periodontol. 2001;72(10):1348-53.

Birn $\mathrm{H}$. The vascular supply of the periodontal membrane. J Period Res. 1966; 1:5168.

Brägger U, Pasquali L, Kornman KS. Remodelling of interdental alveolar bone after periodontal flap procedures assessed by means of computer-assisted densitometric image analysis (CADIA). J Clin Periodontol.1988;15(9):558-64.

Cook DR, Mealey BL, Verrett RG, Mills MP, Noujeim ME, Lasho DJ, Cronin-Jr RJ. Relationship between clinical periodontal biotype and labial plate thickness: an in vivo study. Int J Periodontics Restorative Dent. 2011;31:345-54.

De Sanctis M, Cortellini P, Clauser C, Pini Prato GP. Coronal displacement of the junctional epithelium ad attachmente gain following apically positioned flap with bone resective surgery in dogs. Int J Periodontics Restorative Dent. 1988;8(4):64-76.

Deschner J, Wolff S, Hedderich J, KreuschT, Jepsen S. Dimensional changes of periodontal soft tissues after intrasulcular incision. Clin Oral Invest. 2009;13:401-8. doi: 10.1007/s00784-009-0251-y.

Donath K. Preparation of Histological Sections (by the Cutting-Grinding Technique for Hard Tissue and other Material not Suitable to be Sectioned by Routine Methods) -

\footnotetext{
${ }^{1}$ De acordo com Estilo Vancouver.
} 
Equipment and Methodological Performance. Norderstedt, Germany: EXAKT-Kulzer Publications; 1993.

Fickl S, Zuhr O, Wachtel H, Bolz W, Huerzeler M. Tissue alterations after tooth extraction with and without surgical trauma: a volumetric study in the beagle dog. $\mathrm{J}$ Clin Periodontol. 2008; 35: 356-63. doi: 10.1111/j.1600-051X.2008.01209.x.

Karnovsky M. A formaldehyde-glutaraldehyde fixative of high osmolarity for use in electron microscopy. J Cell Biol. 1965 (27), abstract no 20:137A-138A.

Kon S, Novaes AB, Ruben MP, Goldman HM. Visualization of the microvascularization of the healing periodontal wound IV. Mucogingival surgery: full thickness flap. J Periodontol. 1969;40(8): 441-56.

Lindhe J, Karring T, Araújo MG. The anatomy of periodontal tissues. In: Lindhe J, Lang N, Karring T (Ed.). Clinical Periodontology and Implant Dentistry. $5^{\text {th }}$ ed. Coppenhagen: Blackwell-Publishing, 2008. cap. 1, p.3-48.

Nobuto T, Suwa F, Kono T, Hatakeyama Y, Honjou N, Shirai T, Mitsuyama M, Imai $\mathrm{H}$. Microvascular response in the periosteum following mucoperiosteal flap surgery in dogs: 3-dimensional observation of an angiogenic process. J Periodontol. 2005; 76(8): 1339-45.

Novaes AB Jr, Macedo GO, Suaid FA, Barros RR, Souza SL, Silveira E Souza AM. Histologic evaluation of the buccal and lingual bone plates in anterior dog teeth: possible influence on implant dentistry. J Periodontol. 2011;82(6):872-7. doi: 10.1902/jop.2010.100244.

Pennel BM, King KI, Wilderman MN, Barron JM. Repair of the alveolar process following osseous surgery. J Periodontol. 1967; 38:426-31.

Pfeifer JS. The growth of gingival tissue over denuded bone. J Periodontol. 1963;34:10-6.

Rosling B, Nyman S, Lindhe J. The effect of systematic plaque control on bone regeneration in infrabony pockets. J Clin Periodontol. 1976;3(1):38-53.

Schroeder HE. The Periodonium. Handbook of microscopic anatomy. Berlim: Ed Springer-Verlag. 1986. 
Sciubba JJ, Waterhouse JP, Meyer J. A fine structural comparison of the healing of incisional wounds of mucosa and skin. J Oral Pathol. 1978;7(4):214-27.

Stahl SS. Healing following simulated fiber retention procedures in rats. $J$ Periodontol. 1977; 48(2):67-73.

Stahl SS, Slavkin HC, Yamada L, Levine S. Speculations about gingival repair. J Periodontol. 1972; 43(7):395-402.

Wilderman MN. Repair after a periosteal retention procedure. J Periodontol. 1963;34 :487-503.

Wilderman MN, Pennel BM, King K, Barron JM. Histogenesis of repair following osseous surgery. J Periodontol. 1970;41(10):551-65.

Wilderman MN, Wentz FM, Orban BJ. Histogenesis of repair after mucogingival surgery. J Periodontol. 1960;31(2):283-6.

Wood DL, Hoag PM, Donnenfeld OW, Rosenfeld LD. Alveolar crest reduction following full and partial thickness flaps. J Periodontol. 1972; 43(3):141-4.

Yaffe A, Fine N, Binderman I. Regional accelerated phenomenon in the mandible following mucoperiosteal flap surgery. J Periodontol. 1994; 65(1):79-83. 
ANEXO A - Parecer do Comitê de Ética em Pesquisa

- Universidade Estadual de Maringá

Pró-Reitoria de Pesquisa e Pós-Graduaçäo

Comitê de Conduta Ética no Uso de Animais em Experimentação

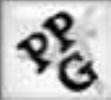

Parecer emitido após reuniäo realizada em:

$10 / 2 / 2009$

Parecer $n^{\circ}$

$008 / 2009$

Pesquisador: Mauricio Guimaräes Araújo

Setor:

DOD

Título:

Protocolo $\mathrm{n}^{\circ} \quad 047 / 2008$

Efeito do enxerto de osso alógeno, xenogênico e aloplástico a preservação do rebordo.

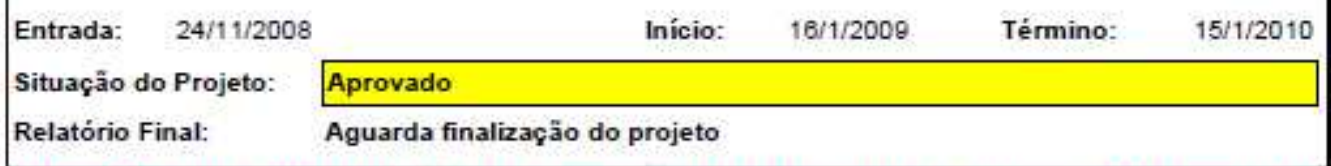

ATENÇAO: este parecer autoriza os proponentes a executarem o protocolo em questão. 0 certificado será emitido após apreciaçäo e aprovação do relatório final.

Considerações e Parecer:

Ro avaliar os esclarecimentos encaminhados pelo protessor pesquisador a respeito das questöes levantadas ao se enalisar, em primeira instäncia, o projeto "EFEITO DO ENXERTO DE OSSO ALOGENO, XENOGÉNICO E

ALOPLASTICO A PRESERVAÇO DO REBORDO:, constatou-se serem satisfatórios, o que permite emitir parecer avorável ao início da pesquisa.

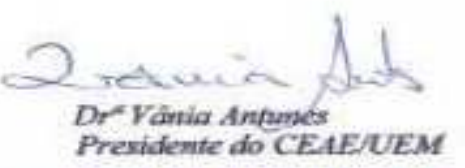

Artigo 10 da Resolução $n^{2}$ 032/2006-CEP: Os projetos analisados seräo enquadrados em uma das seguintes categorias: 1 - aprovado;

il-pendente, quando o CEAE considerar o protocolo e o projeto como aceitáveis, porém com problemas no protocolo, no projeto ou em ambos, e houver recomendaçăo de uma revisảo específica, ou solicitaçăo de modificacão ou informaçâo relevante, que deverá ser atendida em até 60 dias, após o recebimento da comunicaçâo, pelo coordenador do projeto;

III - arquivado, quando o protocolo permanecer pendente, transcorridos 30 dias, após o prazo previsto no inciso II do recebimento da comunicaçảo;

IV - näo aprovado 
G Universidade Estadual de Maringá

Pró-Reitoria de Pesquisa e Pós-Graduação

Comitê de Conduta Ética no Uso de Animais em Experimentação

informaçâo relevante, que deverá ser atendida em até 60 dias, após o recebimento da comunicação, pelo coordenador do projeto:

III - arquivado, quando o protocolo permanecer pendente, transcorridos 30 dias, após o prazo previsto no inciso II do recebimento da comunicaçáo:

IV - näo aprovado 
ANEXO B - Parecer do Comitê de Ética no Uso de Animais

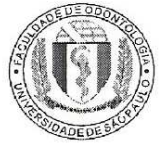

CEUA/FOUSP/Of.08
Universidade de São Paulo

Faculdade de Odontologia

Comissão de Ética no Uso de Animais - CEUA

São Paulo, 26 de março de 2013.

Senhor(a) Pesquisador(a):

Informamos a Vossa Senhoria, que diante de Parecer do Comitê de Conduta Ética no Uso de Animais em Experimentação da Pró-Reitoria de Pesquisa e Pós-Graduação da Universidade Estadual de Maringá CEAE/UEM, parecer emitido após reunião realizada em 10/2/2009 sob o $n^{\circ}$ 008/2009 e ○ protocolo $n^{\circ}$ 047/2008, estamos cientes da aprovação do projeto de pesquisa intitulado "Efeito do enxerto de osso alógeno, xenofênico e aloplástico e preservaçäo do rebordo" de responsabilidade dos Pesquisadores: Maurício Guimarães Araújo e Flávia Sukekava, sob orientação do Prof. Dr. Luiz Antonio Pugliesi Alves de Lima, não havendo nenhuma oposição por parte deste CEUA, com relação a sua realização.

Sendo o que se nos apresentava, valemo-nos da oportunidade para reiterar-lhe os nossos protestos de elevada estima e distinta consideração.

Cordialmente.

Prof. Dr. Jaão Gualberto de Cerqueira Luz Coordenador do CEUA-FOUSP 